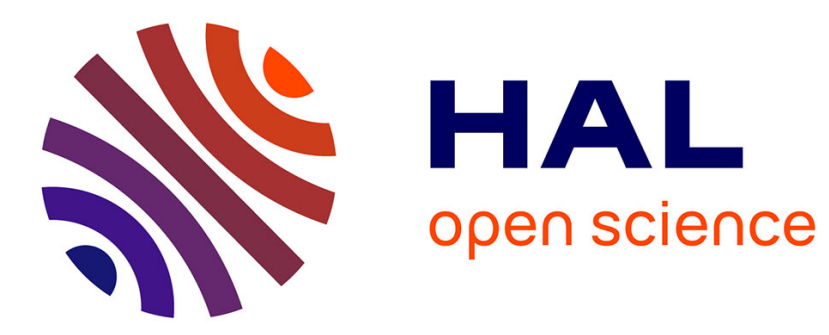

\title{
Frequency Selection for Reflectometry-based Soft Fault Detection using Principal Component Analysis
}

Nour Taki, Wafa Ben Hassen, Nicolas Ravot, Claude Delpha, Demba Diallo

\section{To cite this version:}

Nour Taki, Wafa Ben Hassen, Nicolas Ravot, Claude Delpha, Demba Diallo. Frequency Selection for Reflectometry-based Soft Fault Detection using Principal Component Analysis. Prognostics and Systems Health Management Conference (PHM-Paris 2019), May 2019, Paris, France. hal-02295328

\section{HAL Id: hal-02295328 \\ https://hal-centralesupelec.archives-ouvertes.fr/hal-02295328}

Submitted on 12 Mar 2020

HAL is a multi-disciplinary open access archive for the deposit and dissemination of scientific research documents, whether they are published or not. The documents may come from teaching and research institutions in France or abroad, or from public or private research centers.
L'archive ouverte pluridisciplinaire HAL, est destinée au dépôt et à la diffusion de documents scientifiques de niveau recherche, publiés ou non, émanant des établissements d'enseignement et de recherche français ou étrangers, des laboratoires publics ou privés. 


\title{
Frequency Selection for Reflectometry-based Soft Fault Detection using Principal Component Analysis
}

\author{
Nour TAKI ${ }^{1,2}$ \\ 1. CEA, LIST \\ 2. L2S, CNRS UMR 8506- \\ CentraleSupelec - Univ. Paris \\ Sud \\ 91192 Gif-sur-Yvette, France \\ nour.taki@cea.fr
}

\author{
Wafa BEN HASSEN \\ CEA, LIST \\ 91192 Gif-sur-Yvette, France \\ wafa.benhassen@cea.fr
}

\author{
Nicolas RAVOT \\ CEA, LIST \\ 91192 Gif-sur-Yvette, France \\ nicolas.ravot@cea.fr
}

\author{
Claude DELPHA* \\ Laboratoire des Signaux et Systèmes \\ (L2S) \\ CNRS UMR 8506 - CentraleSupelec \\ - Univ. Paris Sud \\ 91192 Gif Sur Yvette, France \\ claude.delpha@12s.centralesupelec.fr
}

\author{
Demba DIALLO \\ Group of Electrical Engineering of Paris (GeePs) \\ CNRS UMR 8507, CentraleSupelec, \\ Univ. Paris Sud, Sorbonne Univ. \\ 91192 Gif Sur Yvette, France \\ demba.diallo@geeps.centralesupelec.fr
}

\begin{abstract}
This paper introduces an efficient approach to select the best frequency for soft fault detection in wired networks. In the literature, reflectometry method has been well investigated to deal with the problem of soft fault diagnosis (i.e. chafing, bending radius, pinching, etc.). Soft faults are characterized by a small impedance variation resulting in a low amplitude signature on the corresponding reflectograms. Accordingly, the detection of those faults depends strongly on the test signal frequency. Although the increase of test signal frequency enhances the soft fault "spatial" resolution, it provides signal attenuation and dispersion in electrical wired networks. In this context, the proposed method combines reflectometry-based data and Principal Component Analysis (PCA) algorithm to overcome this problem. To do so, the Time Domain Reflectometry (TDR) responses of 3D based-models of faulty coaxial cable RG316 and shielding damages have been simulated at different frequencies. Based on the obtained reflectograms, a PCA model is developed and used to detect the existing soft faults. This latter permits to determine the best frequency of the test signal to fit the target soft fault.
\end{abstract}

Keywords-Time domain reflectometry, Principal component analysis, Wire diagnosis, Soft fault, Frequency selection, Statistical Chart.

\section{INTRODUCTION}

$\mathrm{W}$ ire diagnosis addresses the problem of electrical fault detection, localization and characterization. Various arising technologies are used to resolve this issue [1]. However, the lights are spotted widely on the Time Domain Reflectometry (TDR) method, which utilizes a fast rise time pulse and deals with most industry's wiring issues [2]. Based on the principle of radar, it injects a highfrequency test signal down the wire under test and records the echoes created at each impedance discontinuity such as junctions and faults. The correlation of the obtained signal to the injected one is known as a reflectogram where each peak corresponds to an impedance singularity. The energy of the test signal may be well attenuated due to the presence of cable inhomogeneity, junctions, coupling, splices, etc., and detecting electrical faults becomes complex. This complexity increases in presence of soft faults (i.e. chafing, bending radius, pinching).

In fact, soft faults are characterized by a small impedance variation leading to a low amplitude signature on the corresponding reflectogram. Moreover, in noisy environments such as vibration, high temperature, crosstalk, etc., those faults detection encounter several difficulties. As a solution, further development is needed to make the reflectometry method sensitive enough to detect and locate soft faults. In this context, several post-processing methods have been proposed in [3-5]. A Self-Adaptive Correlation Method (SACM) where the gain is automatically adjusted depending on the fault signature is proposed in [3]. A Signature Magnification by Selective Windowing (SMSW) method is proposed in [4] to select the critical zone based on a predetermined window. In [5], a fusion approach of several post-processing results is proposed where a probabilistic model is developed and used to detect the soft fault. Although interesting methods have been proposed to enhance soft fault diagnosis, they are prone to test signal attenuation and dispersion phenomena.

Moreover, the signature of the soft fault may be invisible on the corresponding reflectogram since the front and back of the fault may cancel each other out when the time width of the test signal is greater than the length of the soft fault [6]. Hence, the choice of the test signal bandwidth is very important and affects the diagnosis performance. Although bandwidth increases the resolution for detecting soft faults, it provides more attenuation. Thereby, a compromise between those two quantities should be defined.

In this paper, a new approach for the frequency selection in the case of soft fault diagnosis is proposed. Indeed, the TDR response has been simulated for several soft fault cases at four different frequencies after which principal component analysis (PCA) is applied to the obtained data where a multivariate statistical test is used to select the proper frequency. 
The remaining of the paper is organized as follows. Section II illustrates the used model in our approach and the simulation results. Section III focuses on the PCA theory and how it is used for Fault Detection and Diagnosis (FDD). Section IV describes the proposed approach for the frequency selection and the obtained results. Section V concludes the paper.

\section{SOFT FAULT DETECTION BASED ON TDR}

Reflectometry techniques rely on the propagation of electrical signals in a transmission line. Indeed, the way in which the signals propagate is related to the physical characteristics of the line. The behavior of the line, at the electrical level, can provide information on the existing faults. The basics of line theory are presented here in order to establish the link between the electrical response of a line and the characteristics of the faults. An RLCG circuit constituted of the following parameters models the highfrequency propagation in a transmission line: resistance $\mathrm{R}$ $(\mathrm{Ohm} / \mathrm{m})$, inductance L $($ Henry $/ \mathrm{m})$, capacitance C $(\mathrm{Farad} / \mathrm{m})$ and conductance $\mathrm{G}$ (Siemens/m). Equations (1) and (2) indicate the variation of the parameters $\mathrm{L}$ and $\mathrm{C}$ as a function of frequency where $\mu_{0}$ is the vacuum magnetic permeability and $\mu_{r}$ is the relative permeability of the conductor. $\mathrm{D}$ and $\mathrm{d}$ are the outer and inner conductor diameters respectively. The parameter $\varepsilon_{0}$ defines the air permittivity and $\varepsilon_{r}$ is the relative permittivity of the dielectric [7]. In the case of loss-free propagation $\mathrm{R}=\mathrm{G}=0$.

$$
\begin{gathered}
\mathrm{L}=\frac{\mu_{r} \mu_{0}}{\pi} \operatorname{acos}\left(\frac{D}{d}\right) \\
\mathrm{C}=\frac{\pi \varepsilon_{r} \varepsilon_{0}}{\operatorname{acosh}\left(\frac{D}{d}\right)}
\end{gathered}
$$

In [8], the complex propagation constant (3) is defined as a function of the radian frequency $\omega=2 \pi f$ (radian/s) and its imaginary part (4), $\beta$ (radian/m), defines the phase constant where $\operatorname{Im}($.$) is the imaginary part operator. The$ solution of the Telegraph's equations gives (5), the characteristic impedance $Z_{c}(\mathrm{Ohm})$ of the line.

The presence of an impedance discontinuity along the line generates reflected waves. Equation (6) gives the reflection coefficient $\Gamma_{f}$ at any discontinuity along the line where $Z_{f}$ is the fault impedance [3]. This parameter is of high importance in the principle of reflectometry.

$$
\begin{gathered}
\gamma(\omega)=\sqrt{(\mathrm{R}+j \omega \mathrm{L})(\mathrm{G}+j \omega \mathrm{C})} \\
\beta=\operatorname{Im}(\gamma) \\
Z_{c}=\sqrt{\frac{R+j \omega L}{G+j \omega C}} \\
\Gamma_{f}=\frac{Z_{f}-Z_{c}}{Z_{f}+Z_{c}}
\end{gathered}
$$

In fact, the propagation velocity (7) and the spatial resolution (8) enabled by a test signal vary with the frequency as shown [9]:

$$
\begin{gathered}
v_{p}(f)=\frac{2 \pi f}{\beta} \\
\Delta=\frac{v_{p}}{B_{T}}
\end{gathered}
$$

where $B_{T}$ is the bandwidth of the test signal.

In the process of understanding the behavior of a pointto-point cable in presence of soft faults, in a noiseless environment, an RG316 coaxial cable with $1 \mathrm{~m}$ length is modeled using 3D simulation software (CST). Then, shielding damage is introduced as shown in Fig. 1 and is defined by three parameters: the length $L_{f}$, the position $x_{f}$ and the angular cutaways $\theta_{f}$. In this case, the length of the fault $L_{f}=5.10^{-3} \mathrm{~m}$ and the position is set at the middle of the cable $\left(x_{f}=0.5 \mathrm{~m}\right)$.

The construction specifications of this cable are given in Table I. Using the formula in (5), $Z_{c} \simeq 45 \Omega$.

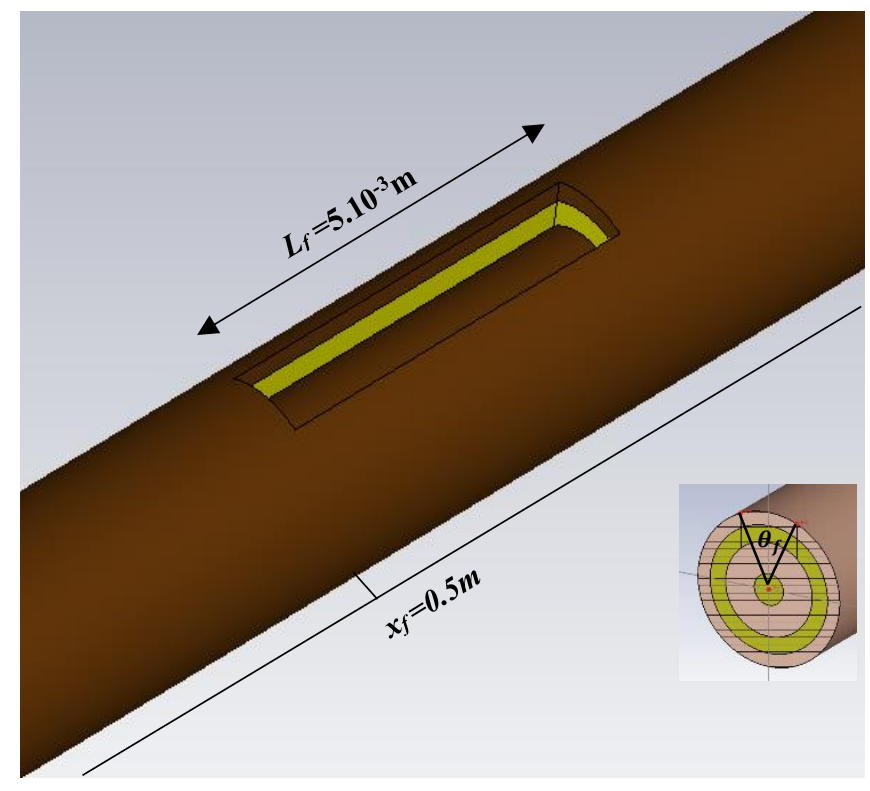

Fig. 1. Fault parameters

TABLE I. RG316 CONSTRUCTION SPECIFICATIONS

\begin{tabular}{|c|c|c|}
\hline Description & Material & Diameter \\
\hline Core & Copper & $0.5110^{-3} \mathrm{~m}$ \\
\hline Dielectric & PTFE & $1.5210^{-3} \mathrm{~m}$ \\
\hline Shield & Copper & $2.0610^{-3} \mathrm{~m}$ \\
\hline Jacket & FEP & $2.5910^{-3} \mathrm{~m}$ \\
\hline
\end{tabular}


First, the healthy cable signature reflectograms are simulated at four different bandwidths, where the bandwidth is defined from DC to a maximal frequency $f_{\max }$. The angular cutaways parameter $\theta_{f}$ is set to one of the three values: $45^{\circ}, 90^{\circ}$ and $180^{\circ}$. The cable is excited using a Gaussian pulse with different maximal frequencies $(1 \mathrm{GHz}$, $2 \mathrm{GHz}, 3 \mathrm{GHz}$ and $4 \mathrm{GHz}$ ).

Figures 2, 3 and 4 represent the signature of the shielding damage with angular cutaways $\theta_{f}=45^{\circ}, \theta_{f}=90^{\circ}$ and $\theta_{f}=180^{\circ}$ respectively and this, for the different maximal frequencies. It is obvious that the signature amplitude and the resolution of the soft fault increase with the frequency as described in (8). Since frequency changes with velocity as described in (7), a shift between the signatures of the same fault at different frequencies is observed on the reflectograms.

As shown in Table II, both the fault severity and the excitation frequency causes the peak amplitudes of the fault signatures to be increased.

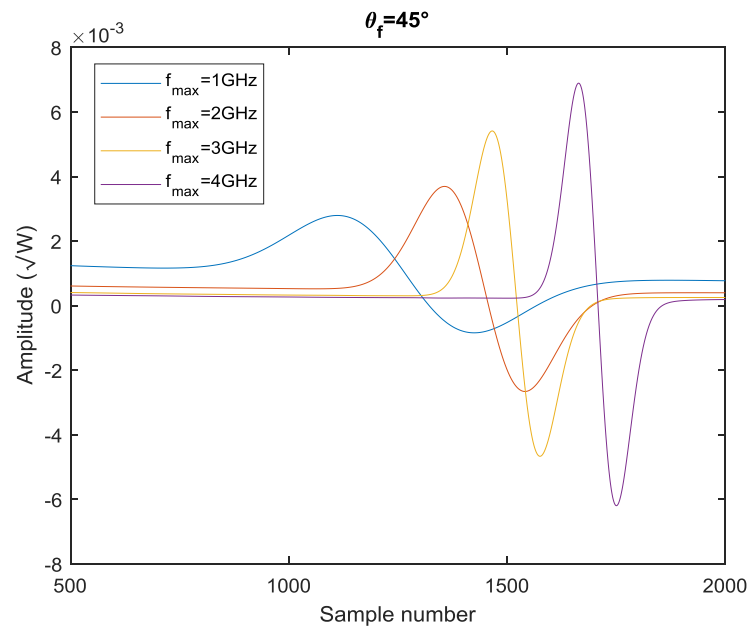

Fig. 2. Soft fault signatures for $\theta_{f}=45^{\circ}$

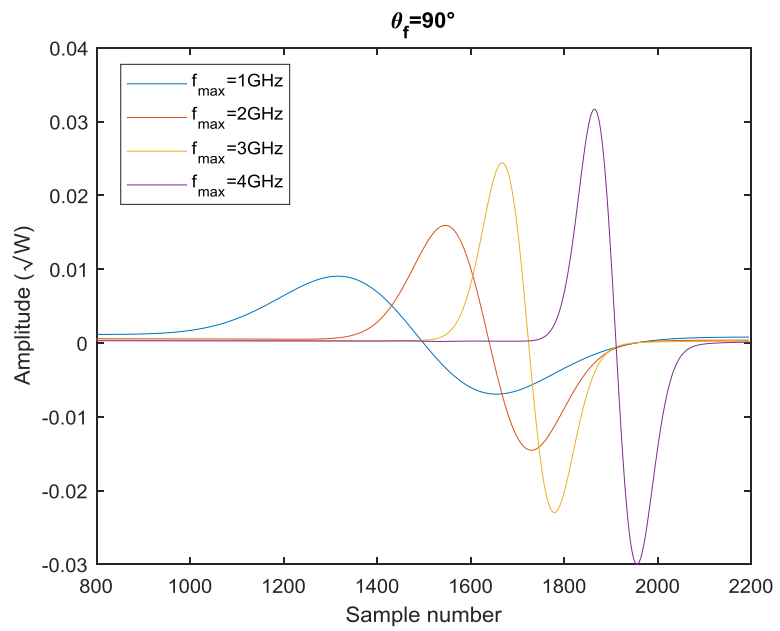

Fig. 3. Soft fault signatures for $\theta_{f}=90^{\circ}$

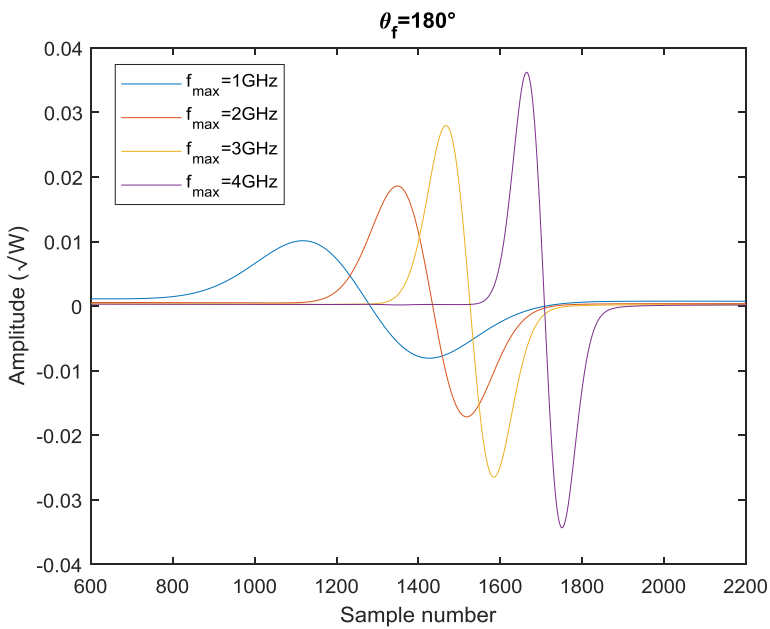

Fig. 4. Soft fault signatures for $\theta_{f}=180^{\circ}$

TABLE II. THE DIFFERENT FAULT SIGNATURE POSITIVE PEAKS

\begin{tabular}{|c|c|c|c|}
\hline \multirow{2}{*}{ Frequency (GHz) } & \multicolumn{3}{|c|}{ Amplitude $\left(\sqrt{\left.\mathbf{w}_{\mathbf{1 0}} \mathbf{1 0}^{-3}\right)}\right.$} \\
\cline { 2 - 4 } & $\mathrm{A}_{45^{\circ}}$ & $\mathrm{A}_{90^{\circ}}$ & $\mathrm{A}_{180^{\circ}}$ \\
\hline $\mathbf{1}$ & 2.79 & 9.04 & 10.13 \\
\hline $\mathbf{2}$ & 3.69 & 15.93 & 18.62 \\
\hline $\mathbf{3}$ & 5.41 & 24.40 & 27.98 \\
\hline $\mathbf{4}$ & 6.89 & 31.67 & 36.22 \\
\hline
\end{tabular}

III. PCA FOR FDD

\section{A. PCA principle}

PCA [10] is a multivariate data-driven statistical modeling technique. It uses information redundancy in a high-dimensional correlated input space to project the original data set into a lower dimensional subspace defined by the principal components (PCs). The main research objective of PCA is the dimensionality reduction of the problem. It considers, in several cases, a substantial variability percentage in the data that can be interpreted using a limited number of components.

The analysis begins with the data matrix $X \in \mathbb{R}^{n \times m}$ which consists of $m$ variables with $n$ observations $(n>m)$. The element $x_{i j}$ is the $i^{\text {th }}$ observation of the $j^{\text {th }}$ variable. In PCA, before processing, $X$ is normalized into $X_{c}$ [11]. Precisely, each vector of $X_{c}$ is calculated as:

$$
\boldsymbol{x}_{\boldsymbol{j} \boldsymbol{c}}=\frac{\boldsymbol{x}_{\boldsymbol{j}}-\mu_{x_{j}}}{\sigma_{x_{j}}}
$$

where $\mu_{x_{j}}$ and $\sigma_{x_{j}}$ are the mean and the standard deviation values of the $j^{\text {th }}$ vector $\boldsymbol{x}_{\boldsymbol{j}}$ respectively.

PCA depends on eigenvalue decomposition of the $X_{c}$ covariance or correlation matrix. Let $C$ denotes the correlation matrix of $X_{c}$ as follows:

$$
C=\frac{1}{n-1} X_{c}^{T} X_{c}
$$

where $(.)^{T}$ is the transpose operator.

By means of Singular Value Decomposition (SVD), one can write $C$ as: 


$$
C=P \Lambda P^{T}, \text { where } P P^{T}=P^{T} P=I_{m \times m}
$$

where $P=\left[\boldsymbol{p}_{1}, \boldsymbol{p}_{2}, \ldots, \boldsymbol{p}_{\boldsymbol{m}}\right] \in \mathbb{R}^{\mathrm{m} \times \mathrm{m}}$ is the PCA loading matrix such that its columns $\boldsymbol{p}_{j}$ are the eigenvectors of the correlation matrix $C$. Vectors $p_{j}$ are orthonormal and they are also known as the weight vectors. The matrix $\Lambda$ is diagonal with the elements $\left\{\lambda_{j}\right\}$ for $1 \leq j \leq m$ are the eigenvalues of $C$ sorted in descending order.

According to [12-14], PCA decomposes the data matrix into two parts; the first explains the system variation while the second encapsulates the residual information (noise):

$$
X_{c}=T P^{T}=T_{\ell} P_{\ell}^{T}+\tilde{T} \tilde{P}^{T}
$$

where $T$, highlighting the relationship between the samples in $X_{c}$, stands for the principal component score matrix and the superscript $(\sim)$ is the residual matrix operator.

The selection of the number $\ell$ (with $\ell \leq m$ ) of principal components to retain is considered as a matter of high importance. Different methods had been used for this purpose [15-16]. Cumulative Percent Variance (CPV) method [17] is used in this paper to set $\ell$ as the number of PCs cumulatively contributing to more than 90 percent of the data variability:

$$
C P V(\ell)=\frac{\sum_{l}^{\ell} \lambda_{k}}{\sum_{l}^{m} \lambda_{k}} \geq 90 \%
$$

\section{B. PCA-based FDD}

Fault detection is to figure out if a fault has occurred or not. The first step here is to have the normal operating data upon which the PCA model will be established. This model is utilized then to examine new measurement data. Two statistical methods are used here. The Q (or Squared Prediction Error SPE) and the Hotelling $\mathrm{T}^{2}$ statistics [13].

PCA-based FDD includes two phases. First, the training phase where data are collected during fault-free operation and PCA model is developed. Second, the monitoring phase, i.e., fault detection is handled using the monitoring statistics and fault diagnosis will be managed through contribution plots.

New measurements $X_{\text {new }}$ will be projected into the framework spanned with the loading matrix $P_{\ell}$. The new scores $T_{\text {new }}$ and the residual $\widetilde{T}_{n e w}$ are calculated according to (14) and (15). Then, the $Q$ and $T^{2}$ statistical values in (16) and (17) are used for evaluating the fault presence. They display the variations that are not interpretable by the retained $\mathrm{PCs}$ in the residual and the principal subspaces respectively.

$$
\begin{gathered}
T_{\text {new }}=X_{\text {new }} P_{\ell} \\
\tilde{T}_{\text {new }}=X_{\text {new }}\left(I-P_{\ell} P_{\ell}^{T}\right) \\
\mathrm{Q}=\tilde{T}_{\text {new }} \tilde{T}_{\text {new }}{ }^{T}
\end{gathered}
$$

$$
\mathrm{T}^{2}=\sum_{l}^{\ell}\left(\frac{t_{j}}{\lambda_{j}}\right)^{2}
$$

where $t_{j}$ is the $j^{\text {th }}$ column vector of $T_{n e w}$.

In the case of an abnormal event, the $\mathrm{Q}$ and $\mathrm{T}^{2}$ statistic values will be greater than the confidence limits $Q_{\alpha}$ and $T_{\alpha}^{2}$ respectively. Those limits are calculated using the healthy original data that constructs the PCA model:

$$
\begin{gathered}
Q_{\alpha}=z_{1}\left[\frac{c_{\alpha} \sqrt{2 z_{2} h_{0}^{2}}}{z_{1}}+1+\frac{z_{1} h_{0}\left(h_{0}-1\right)}{z_{1}^{2}}\right]^{\frac{1}{h_{0}}} \\
z_{i}=\sum_{\mathrm{j}=\ell+1}^{m} \lambda_{\mathrm{j}}^{i} \quad i=1,2,3 \\
h_{0}=1-\frac{2 z_{1} z_{3}}{3 z_{2}^{2}} \\
T_{\alpha}^{2}=\frac{\ell(n-\ell)}{(n-\ell)} F_{\ell, n-\ell, \alpha}
\end{gathered}
$$

where $c_{\alpha}$ is the critical value of the normal distribution at $\alpha$ significance level and $F_{\ell, n-\ell, \alpha}$ is the Fisher-Snedecor distribution critical value.

If at a specific sample the $\mathrm{Q}$ or $\mathrm{T}^{2}$ value falls outside the confidence limit, then there exists an abnormality. We can inspect the inputs (responsible variables) that highly influence their residual. Contribution plots are used for this purpose.

\section{RESULTS AND DISCUSSIONS}

The reference, healthy performance, representation of the data is given by (22). $X$ is formed up of four variables. Each variable $\bar{R}_{f G H z}$ is a column vector of the matrix and corresponds to the cable healthy TDR response at the frequency $f(1 \mathrm{GHz}, 2 \mathrm{GHz}, 3 \mathrm{GHz}$ and $4 \mathrm{GHz}$ respectively). The number of samples for each variable $\bar{R}_{f G H z}$ is 4101 , i.e., $X \in \mathbb{R}^{4101 \times 4}$.

$$
X=\left[\begin{array}{llll}
\bar{R}_{1 G H z} & \bar{R}_{2 G H z} & \bar{R}_{3 G H z} & \bar{R}_{4 G H z}
\end{array}\right]
$$

The obtained data matrix $X$ is then used for the construction of the PCA model according to (9), (10), (11) and (12).

Table III shows the PCs coefficients, also known as loadings. Table IV indicates that the cumulative variance of the first two scores is $98.64 \%$ that is greater than the lower limit. This implies that the observed variables are highly correlated. Using (13), the data is well described by a two principal component model. Thus, $\ell$ is equal to two.

The new measurement data set corresponds to the faulty modeled cases. It has four vectors such that $X_{\text {new }}=\left[\begin{array}{lll}\mathbf{x}_{1} & \mathbf{x} 2 & \mathbf{x} 3\end{array}\right.$ $\mathbf{x} 4$ ]. Each one of the four variables is a concatenated vector of the fault signature data $\left(\theta_{f}=45^{\circ}, \theta_{f}=90^{\circ}\right.$ and $\left.\theta_{f}=180^{\circ}\right)$ 
at the same frequency. The new data matrix is defined as follows:

$$
\begin{aligned}
& X_{\text {new }}=\left[\begin{array}{llll}
\bar{R}_{45^{\circ}{ }_{1 G \mathrm{~Hz}}} & \bar{R}_{45^{\circ}{ }_{2 \mathrm{GH}}} & \bar{R}_{45^{\circ}{ }_{3 \mathrm{GHz}}} & \bar{R}_{45^{\circ}{ }_{4 G \mathrm{~Hz}}} \\
\bar{R}_{90^{\circ}{ }_{1 G \mathrm{~Hz}}} & \bar{R}_{90^{\circ}{ }_{2 G \mathrm{~Hz}}} & \bar{R}_{90^{\circ}{ }_{3 G \mathrm{~Hz}}} & \bar{R}_{90^{\circ}{ }_{4 G \mathrm{~Hz}}} \\
\bar{R}_{180^{\circ}{ }^{\circ} \mathrm{GH}} & \bar{R}_{180^{\circ}{ }^{\circ} \mathrm{GHz}} & \bar{R}_{180^{\circ}{ }_{3 G \mathrm{~Hz}}} & \bar{R}_{180^{\circ}{ }_{4 G \mathrm{~Hz}}}
\end{array}\right] \\
& =\left[\begin{array}{llll}
\mathbf{x}_{1} & \mathbf{x}_{2} & \mathbf{X}_{3} & \mathbf{X}_{4}
\end{array}\right]
\end{aligned}
$$

where $\bar{R}_{\theta_{f}}{ }_{f}$ describes the fault signature data vector with angular cutaways $\theta$ and frequency $f$.

The constructed PCA model is then used to check the new measurement data. To do so, the differences between the new measurement data and their projections into the constructed model are then subjected to the $\mathrm{Q}$ and Hoteling's $\mathrm{T}^{2}$ statistical tests. The $95 \%$ confidence limits of those tests are calculated according to (18-21). Thus, $Q_{\alpha}=$ 22.25 and $T_{\alpha}^{2}=26.92$.

According to (14-17), the SPE and the $\mathrm{T}^{2}$ values of each new measurement sample are calculated. Figures 5 and 6 present the $\mathrm{Q}$ and the $\mathrm{T}^{2}$ control charts respectively, with the dashed red line representing the $95 \%$ confidence limit. It is shown that $Q_{\alpha}$ have been exceeded by some samples (6508, 6630, 10620 and 10730) and $T_{\alpha}^{2}$ by the samples (10620 and 10730). This indicates that faults have occurred.

Plotting the contribution charts in Fig. 7 and Fig. 8 of the indicated faulty samples permits to know the variable $\left(\mathbf{x}_{1}, \mathbf{x}_{2}, \mathbf{x}_{3}\right.$ or $\left.\mathbf{x}_{4}\right)$ that highly influences their $\mathrm{Q}$ and $\mathrm{T}^{2}$ values. Thereby, the selection of the relevant frequency is performed by $\mathrm{Q}$ and Hotelling $\mathrm{T}^{2}$ control tests. The sample 6508 in Fig.7 is related only to the Q test whereas the sample 10620 in Fig.8 is related to the two tests. The contribution of the first variable $\mathbf{x}_{\mathbf{1}}$ is almost neglected with respect to the other variables; hence, it does not appear in the plots.

If we look at Figures 5, 7 and 8, we can draw the following concluding remarks:

- for $\theta_{f}=45^{\circ}$, the fault cannot be detected whatever the frequency.

- for $\theta_{f}=90^{\circ}$ and $\theta_{f}=180^{\circ}$, the faults are undetectable at 1,2 or $3 \mathrm{GHz}$ frequencies.

- for $\theta_{f}=90^{\circ}$ and $\theta_{f}=180^{\circ}$, at $4 \mathrm{GHz}$, the faults are clearly detected.

However, Figures 6,7 and 8 show that the fault is only detectable for $\theta_{f}=180^{\circ}$ at $4 \mathrm{GHz}$.

Thanks to the simulation results of a $1 \mathrm{~m}$ length RG316 coaxial cable with a shielding damage with 3 severity levels $\left(45^{\circ}, 90^{\circ}\right.$ and $\left.180^{\circ}\right)$, the combination of reflectometry and PCA coupled to $\mathrm{Q}$ and $\mathrm{T}^{2}$ statistics shows that:

- the highest frequency $(4 \mathrm{GHz})$ leads to the best fault detection capability for the two largest severities if $\mathrm{Q}$ test is used and the largest severity detection if $\mathrm{T}^{2}$ test is used.
- for the lowest fault severity, the Q and $\mathrm{T}^{2}$ in the PCA framework fail to detect the fault.

- Q test is more suitable than $\mathrm{T}^{2}$ to be used in our case study since it is able to detect more faults.

TABLE III. EIGENVECTORS

\begin{tabular}{|c|c|c|c|c|}
\hline $\begin{array}{c}\text { PCs } \\
\text { Coefficients }\end{array}$ & PC1 & PC2 & PC3 & PC4 \\
\hline $\mathbf{1}$ & 0.89 & -0.44 & -0.02 & -0.05 \\
\hline $\mathbf{2}$ & 0.36 & 0.73 & -0.56 & 0.11 \\
\hline $\mathbf{3}$ & 0.22 & 0.48 & 0.67 & -0.49 \\
\hline $\mathbf{4}$ & 0.14 & 0.15 & 0.46 & 0.85 \\
\hline
\end{tabular}

TABLE IV. PCA MODEL VARIANCE RESULTS

\begin{tabular}{|c|c|c|}
\hline $\begin{array}{c}\text { PC } \\
\text { Number }\end{array}$ & $\begin{array}{c}\text { Variance } \\
\text { percentage }\end{array}$ & $\begin{array}{c}\text { Accumulated } \\
\text { percentage }\end{array}$ \\
\hline $\mathbf{1}$ & 95.37 & 95.37 \\
\hline $\mathbf{2}$ & 3.27 & 98.64 \\
\hline $\mathbf{3}$ & 1.03 & 99.68 \\
\hline $\mathbf{4}$ & 0.31 & 100.00 \\
\hline
\end{tabular}

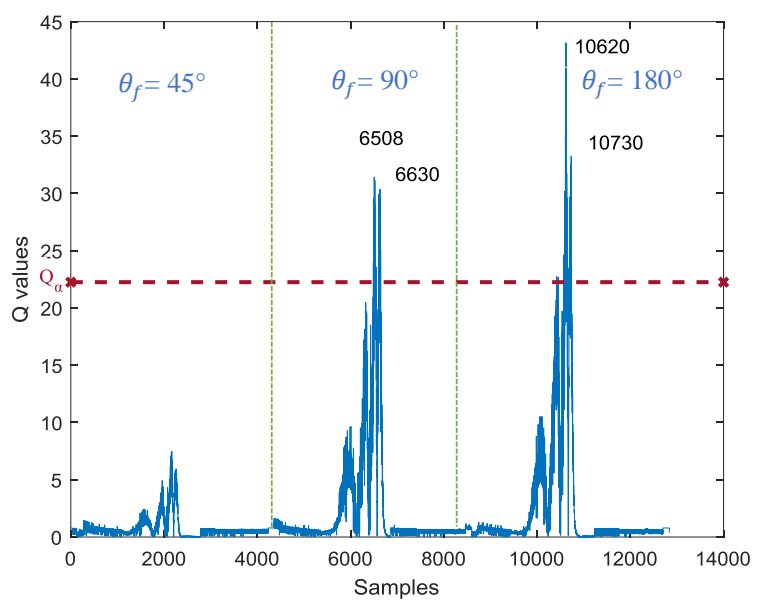

Fig. 5. $Q$ values of the new measurement samples

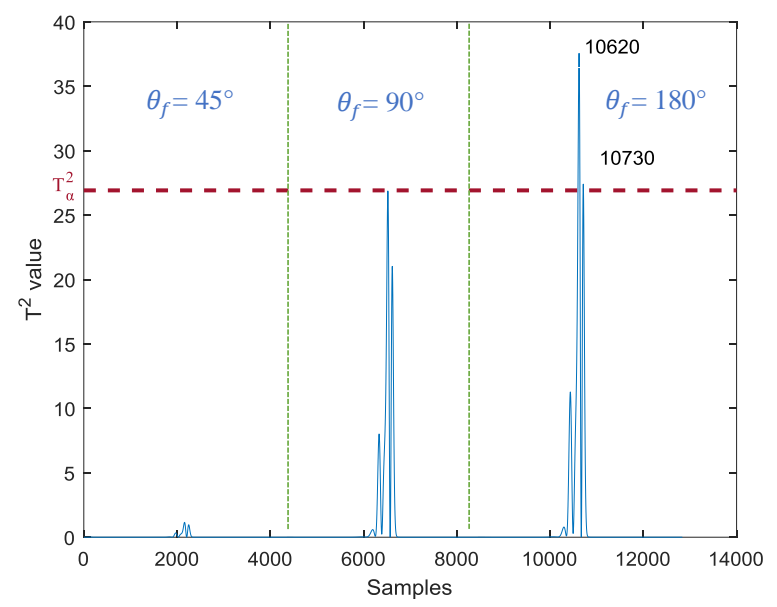

Fig. 6. $T^{2}$ values of the new measurement samples 


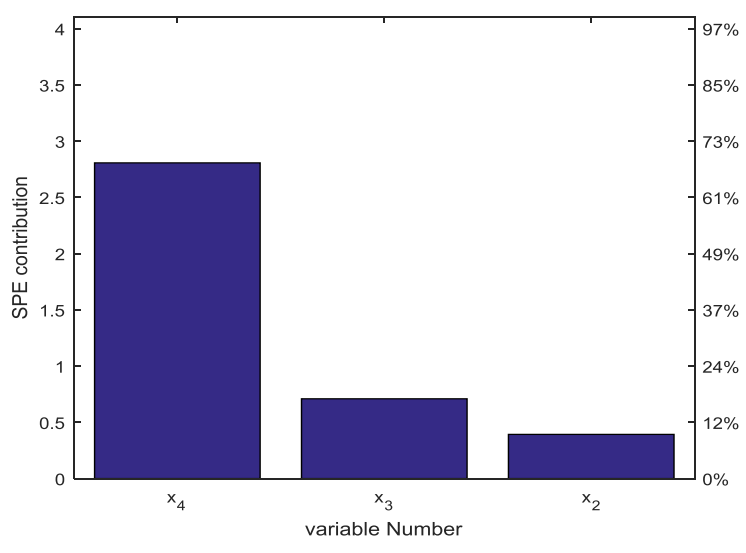

Fig. 7. Contribution plot of the sample 6508

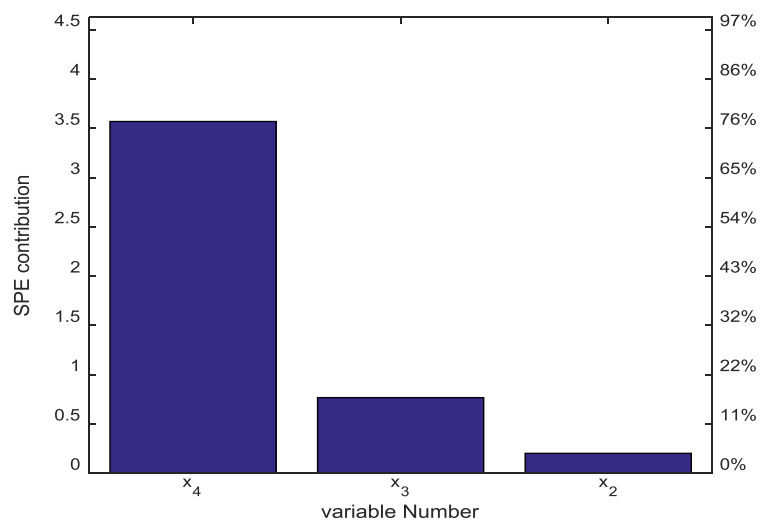

Fig. 8. Contribution plot of the sample 10620

\section{CONCLUSION}

This paper introduces an efficient approach to select the best frequency bandwidth for soft fault detection in wired networks based on a judicious combination of reflectometry and Principal Component Analysis.

In practice, the expert configures and calibrates the Vector Network Analyzer (VNA) at a given frequency and records the healthy cable measurement. Measurements at the same frequency as before will be done on a faulty cable. Analysis of the measurements will be established at this frequency on the PC. If the fault is not detected, the expert must redo the measurements at a higher frequency and so on. Therefore, there is a loss of information and time in addition to the subjectivity of the decision-making.

The proposed method permits to configure and calibrate the VNA at different frequencies. It performs measurements on different frequencies for the healthy case. After which the PCA model is established. It performs the real-time measurements at different frequencies. If a difference is detected between the model and the real-time data, the contribution of each variable (i.e. frequencies) to this difference is calculated. The algorithm then chooses the most relevant frequency to monitor the non-frank defect in the perspective of a prognosis. The advantages are thus time saving and objectivity of the decision-making. Furthermore, monitoring the evolution of defects in the prognosis perspective.

The simulation results are in coherence with the previously known rule that for short cables, the higher the frequency, the better it is for the fault detection. In future works, this approach will be applied to another set of cables with different operating conditions and different fault types. Other statistics will also be evaluated to cope with the detection of incipient faults.

\section{REFERENCES}

[1] F. Auzanneau, "Wire troubleshooting and diagnosis: review and perspectives", Progress In Electromagnetics Research B, vol. 49, pp. 253-279, 2013.

[2] C. Furse, Y. C. Chung, C. Lo, P. Pendayala. "A critical comparison of reflectometry methods for location of wiring faults", Journal of Smart Structures and Systems, 2(1), pp. 25-46, 2006.

[3] S. Sallem, N. Ravot, "Self-adaptive correlation method for soft defect detection in cable by reflectometry", Proceeding of 2014 IEEE Sensors Conference, 2114-2117, Valencia, Spain, 2014.

[4] S. Sallem, N. Ravot, "Self-adaptive correlation method for soft defect detection in cable by reflectometry". In Sensors, 2014 IEEE, pp. 2114-2117, 2014.

[5] W. Ben Hassen, M. Gallego Roman, B. Charnier, N. Ravot, A. Dupret, A. Zanchetta, F. Morel, "Embedded OMTDR Sensor for Small Soft Fault Location on Aging Aircraft Wiring Systems", Procedia Engineering, vol. 168, pp. 1698-1701, 2016.

[6] L. A. Griffiths, R. Parakh, C.Furse, B. Baker, "The invisible fray: A critical analysis of the use of reflectometry for fray location". IEEE Sensors Journal, 6(3), 697-706, 2006.

[7] W. Ben Hassen, N. Ravot, A. Dupret, A. Zanchetta, F. Morel, L. Pillon, C. Chuc, "OMTDR-based embedded cable diagnosis for mutliple fire zones detection and location in aircraft engines". In Sensors, 2017 IEEE (pp. 1-3), 2017.

[8] M. B. Steer, "Microwave and RF design: a systems approach". SciTech Pub, 2010.

[9] M. Kafal, A. Cozza, L. Pichon, "Locating faults with high resolution using single-frequency TR-MUSIC processing". IEEE Transactions on Instrumentation and Measurement, 65(10), 2342-2348, 2016.

[10] R. Penha, J.W. Hines, "Using principal component analysis modeling to monitor temperature sensors in a nuclear research reactor". In Proceedings of the 2001 Maintenance and Reliability Conference (MARCON 2001), Knoxville, TN, 2001.

[11] H. Wang, Z. Song, P. Li, "Fault detection behavior and performance analysis of principal component analysis based process monitoring methods". Industrial \& Engineering Chemistry Research, 41(10), 2455-2464, 2002.

[12] T. J. McAvoy, "Intelligent "Control" applications in the Process Industries". Annual Reviews in Control, 26, pp.75-86, 2002.

[13] D. Slišković, R. Grbić, Ž. Hocenski, "Multivariate statistical process monitoring". Tehnicki Vjesnik-Technical Gazette, 19(1), 33-41, 2012.

[14] J. Harmouche, C. Delpha, D. Diallo, "Incipient fault detection and diagnosis based on Kullback-Leibler divergence using principal component analysis: Part I". Signal Processing, 94, 278-287, 2014.

[15] G. Diana, C. Tommasi, "Cross-validation methods in principal component analysis: a comparison. Statistical Methods and Applications", 11(1), 71-82, 2002.

[16] R. B. Cattell, "The scree test for the number of factors". Multivariate behavioral research, 1(2), 245-276, 1966.

[17] J. L. Horn, "A rationale and test for the number of factors in factor analysis". Psychometrika, 30(2), 179-185, 1965. 